\title{
Sifat Campuran Herbisida Berbahan Aktif Bentazon dan MCPA Terhadap Gulma Daun Lebar, Teki dan Rumput
}

\section{Characteristics of herbicide mixtures of Bentazon and MCPA on Rice Field Weeds Broad leave, Sedges and Grasses}

\author{
Uum Umiyati*, Dedi Widayat, Dani Riswandi dan Reza Amalia \\ Faculty of Agriculture, Universitas Padjajaran, Bandung, Indonesia \\ ${ }^{*}$ Corresponding author: uum.umiyati@unpad.ac.id
}

Received: August 25, 2020; Accepted: March 22, 2021; Published: April 1, 2021

\begin{abstract}
Weed control using a single herbicide with same active ingredients can add the risk of weed resistance. Using mixed herbicides can increase the spectrum of weeds controlled, and inhibit weed resistance. Herbicide mixture with two or more types of active ingredients will show the interactions between one and another ingredient. These interactions could be synergistic, antagonistic, and additive. The research was to determine the response of mixed herbicide Bentazon, MCPA $460 \mathrm{~g}$. $\mathrm{L}^{-1}$ and their mixed characteristic. This experiment was conducted from June until August 2019 in the greenhouse at the Faculty of Agriculture, Universitas Padjadjaran. The treatment consisted of three types of herbicides with six dose levels, namely a single herbicide of Bentazon $400 \mathrm{~g} . \mathrm{L}^{-1}$ and MCPA $60 \mathrm{~g} . \mathrm{L}^{-1}(4 ; 2 ; 1 ; 0.5$; 0.25; 0 L.ha-1 $)$, a mixed herbicide Bentazon MCPA 460 g.L ${ }^{-1}\left(5 ; 2.5 ; 1.25 ; 0.625 ; 0.3215\right.$; 0 L.ha $\left.{ }^{-1}\right)$ with four replications. The target weeds tested were Spenochlea zeylanica, Ludwigia hyssopifolia, Fimbristylis miliacea, and Cyperus iria was taken from the Ciparay area. Data were analysed by linear regression analysis and multiplicative survival model (MSM) method to determine the LD50 treatment and expectation. The result showed that compound herbicides of Bentazon and MCPA LD50 treatment $\left(0,3857 \mathrm{~g} \cdot \mathrm{ha}^{-1}\right)$ had smaller value than LD50 expectation $(0,6943$ g.ha ${ }^{-1}$ ) with a ecotoxicity value of $1.8(>1)$, so that the herbicide mixture was synergistic.
\end{abstract}

Key words: LD50; toxicity; weed

Cite this as: Umiyati, U., Widayat, D., Riswandi, D. \& Amalia, R. (2021). Sifat campuran herbisida berbahan aktif bentazon dan MCPA terhadap gulma daun lebar, teki dan rumput. Agrosains : Jurnal Penelitian Agronom, 23(1), 1-5. DOI: http://dx.doi.org/10.20961/agsjpa.v23i1.43981

\section{PENDAHULUAN}

Kehadiran gulma menyebabkan terjadinya kompetisi dengan tanaman dalam memperoleh air, unsur hara, dan cahaya matahari sehingga tanaman budidaya tidak menunjukkan hasil yang sesuai dengan potensinya. Beberapa gulma daun lebar dan teki yang umum pada lahan budidaya padi sawah yaitu Ludwigia hyssopifolia, Sphenoclea zeylanica, Cyperus iria, dan Fimbristylis miliacea. Kerugian yang ditimbulkan akibat gulma tersebut pada padi sawah sebesar $10-15 \%$ bahkan apabila tidak dikendalikan akan mencapai 86\% (Zarwazi et al., 2016). Besarnya kerugian yang disebabkan oleh gulma, maka dibutuhkan pengendalian untuk menekan pertumbuhan gulma yaitu melalui pendekatan sistem budidaya dan teknik pengendalian gulma.

Penggunaan herbisida saat ini banyak diminati oleh petani, terutama untuk lahan pertanian yang luas dan kekurangan tenaga pekerja (Umiyati et al., 2018). Aplikasi herbisida dalam jangka panjang dengan bahan aktif akan menimbulkan resiko resistensi gulma. Saat ini terdapat 500 spesies gulma yang terbukti mengalami resistensi akibat pemakaian herbisida tunggal (Jones \& Owen, 2021). Oleh karena itu, upaya yang dapat dilakukan untuk menekan resistensi yaitu dengan penggunaan herbisida campuran (MacLaren et al., 2020).
Herbisida campuran dilakukan dengan mencampurkan bahan aktif yang berbeda untuk mendapatkan spektrum pengendalian yang lebih luas, menghambat terjadinya resistensi gulma, mengurangi residu pada tanaman dan tanah juga dapat lebih menghemat biaya, tenaga kerja dan waktu dalam pertanian intensif (Shekhawat et al., 2020). Menurut Ferreira et al., (2020) bahwa pencampuran herbisida yang optimal akan bertindak secara sinergis yaitu dapat meningkatkan aktivitas pada spesies sasaran gulma dan penurunan toksisitas pada tanaman (peningkatan selektivitas). Namun, tidak semua hasil pencampuran herbisida bersifat sinergis. Untuk itu, setiap campuran herbisida diperlukan pengujian agar dapat diketahui sifat aktivitasnya.

Herbisida Bentazon merupakan herbisida yang masuk kedalam kelompok Benzothiadiazoles yang memiliki cara kerja sebagai penghambat fotosintesis dalam fotosistem II. Herbisida 2-methyl-4clorophenoxyacetic acid (MCPA) termasuk kedalam kelompok phenoxy acetic acid yang bekerja dengan auksin sintesis sehingga dapat mengganggu pertumbuhan gulma (Moshiur Rahman, 2012). Pencampuran bahan aktif Bentazon $400 \mathrm{~g} \cdot \mathrm{L}^{-1}$ dan MCPA $60 \mathrm{~g} . \mathrm{L}^{-1}$ merupakan salah satu cara yang dapat digunakan untuk mengendalikan gulma pada padi 
sawah. Menurut Polansky \& Guntoro, (2016), herbisida campuran Bentazon dan MCPA dapat mengendalikan beberapa jenis gulma golongan daun lebar seperti Ludwigia hyssopifolia, Sphenoclea zeylanica dan gulma teki yaitu Fimbristylis miliace dan Cyperus iria. Herbisida MCPA diaplikasikan saat purna tumbuh dan bersifat sistemik, dapat mengendalikan jenis gulma berdaun lebar dan rumput. Herbisida Bentazon diaplikasikan saat purna tumbuh bersifat kontak dapat mengendalikan gulma berdaun lebar dan teki dari famili Cyperaceae (Garrigou et al., 2021). Penelitian ini bertujuan untuk mengetahui respon campuran herbisida Bentazon MCPA 460 g. $\mathrm{L}^{-1}$ dan karakteristik campurannya.

\section{BAHAN DAN METODE}

Penelitian dilaksanakan di rumah plastik Fakultas Pertanian, Universitas Padjadjaran, Kecamatan Jatinangor, Kabupaten Sumedang, Jawa Barat mulai bulan Juni-Agustus 2019. Bahan yang digunakan yaitu herbisida tunggal berbahan aktif Bentazon $400 \mathrm{~g} . \mathrm{L}^{-1}$ dan MCPA 60 g.L. $\mathrm{L}^{-1}$, herbisida campuran dengan kandungan bahan aktif Bentazon dan MCPA dengan konsentrasi sebesar 460 g.L-1. Propagul gulma yang digunakan sebagai gulma uji adalah gulma yang dominan tumbuh dilahan sawah meliputi gulma golongan daun lebar terdiri dari spesies Ludwigia hyssopifolia dan Sphenoclea zeylanica, gulma golongan teki yaitu Cyperus iria dan Fimbristylis miliacea. Gulma tersebut diperoleh dari kebun percobaan sawah Ciparay. Media tanam yang digunakan pada penelitian ini berasal dari lahan sawah dengan jenis tanah aluvial di sekitar wilayah kampus Universitas Padjadjaran.

Rancangan percobaan dilakukan menggunakan metode eksperimental dengan 18 perlakuan dan diulang sebanyak empat ulangan. Perlakuan pada percobaan yaitu terdiri dari tiga jenis herbisida dengan enam tingkat dosis, yaitu herbisida tunggal Bentazon 400 g.L $\mathrm{L}^{-1}$ dan MCPA 60 g.L.-1 $\left(4 ; 2 ; 1 ; 0,5 ; 0,25 ; 0\right.$ L.ha $\left.^{-1}\right)$, herbisida campuran Bentazon + MCPA 460 g.L L $^{-1}(5 ; 2,5 ; 1,25$; 0,625; 0,3215; 0 L.ha ${ }^{-1}$ ). Perbandingan dosis yang diuji baik dosis herbisida tunggal maupun herbisida campuran adalah ( $\mathrm{X}$ dosis, $1.2 \mathrm{X}$ dosis, $1 / 4 \mathrm{X}$ Dosis, $1 / 8$ $X$ Dosis dan $1 / 16 X$ Dosis), sedangkan $X$ dosis untuk herbisida tunggal Bentazon $400 \mathrm{~g} . \mathrm{L}^{-1}$ dan $60 \mathrm{~g} . \mathrm{L}^{-1}$ adalah 4 L.ha $^{-1}$. $X$ dosis untuk campuran herbisida dengan bahan aktif Bentazon + MCPA, masing-masing kedua campuran bahan aktif sebesar $460 \mathrm{~g} . \mathrm{L}^{-1}$ adalah 5 L.ha-1.

Pengamatan dan analisis dilakukan hingga kerusakan gulma mencapai $50 \%$ untuk setiap individu gulma yang diuji dan diamati secara visual. Pemanenan gulma dilakukan pada 10-14 hari setelah aplikasi (HSA). Menurut Dey \& Pandit, (2020) bahwa gulma dipisahkan antara bagian yang kering dan masih segar. Masingmasing perlakuan dimasukkan dalam amplop yang terpisah dan diberi label, kemudian dioven pada suhu $80^{\circ} \mathrm{C}$ selama 48 jam, selanjutnya ditimbang untuk mendapatkan bobot kering.

Gulma yang digunakan sebagai gulma uji adalah Cyperus iria dan Fimbristylis miliacea, dimana gulma tersebut merupakan tanaman tipe C4 yang memiliki tingkat efisiensi fotosintesis yang rendah dan boros dalam penggunaan air, menyebabkan gulma tersebut sebagai kompetitor bagi tanaman padi untuk menggunakan nutrisi dari dalam tanah, sedangkan Ludwigia hyssopifolia dan Sphenoclea zeylanica termasuk kedalam golongan tanaman C3 seperti halnya tanaman padi. Tumbuhan C4 mempunyai keunggulan toleran terhadap kondisi panas, kering, intensitas cahaya tinggi, efisiensi konsumsi air tinggi dan efisiensi konsumsi nitrogen tinggi, sehingga perkembangan gulma tersebut sangat cepat (Shekhawat et al., 2020).

Data bobot kering yang diperoleh kemudian dikonversi menjadi nilai persen kerusakan. Persen kerusakan dihitung berdasarkan tingkat kerusakan yang ditimbulkan oleh herbisida. Persen kerusakan dapat dihitung dengan menggunakan rumus (Dey \& Pandit, 2020):

$\%$ Kerusakan $=\frac{1-\text { Bobot kering perlakuan }}{\text { Bobot kering kontrol }} \times 100 \%$

Persamaan regresi yang didapat digunakan untuk menentukan nilai LD50 dari perlakuan herbisida yang diaplikasikan pada empat jenis gulma Ludwigia hyssopifolia, Sphenoclea zeylanica, Cyperus iria dan Fimbristylis miliacea. Persen kerusakan yang diperoleh selanjutnya dikonversi ke dalam nilai probit. Dari nilai probit $(y)$ dan log dosis $(x)$ akan diperoleh persamaan regresi linier sederhana dengan menggunakan program SAS. Kemudian dari persamaan ini didapat nilai LD50 herbisida MCPA 60 g.L $\mathrm{L}^{-1}$, Bentazon 400 g.L $\mathrm{L}^{-1}$, dan campuran masing-masing terhadap gulma sasaran.

Nilai LD50 ini selanjutnya akan dianalisis dengan model MSM (Multiplicated Survival Model) untuk mengetahui apakah terdapat aktivitas antagonisme pada pencampuran herbisida. Model MSM digunakan untuk menguji campuran dua atau lebih herbisida yang memiliki cara kerja (mode of action) berbeda. Nilai harapan campuran dinyatakan sebagai $P(A+B)=P(A)+$ $P(B)-P(A)(B)$, dimana $P(A+B)$ adalah nilai persen kerusakan gulma dari herbisida campuran. Dalam penelitian ini, $P(A+B)$ adalah persen kematian gulma dari herbisida campuran MCPA $60 \mathrm{~g} . \mathrm{L}^{-1}$,dan Bentazon 400 g. $\mathrm{L}^{-1}, \mathrm{P}(\mathrm{A})$ adalah persen kerusakan gulma oleh herbisida MCPA $60 \mathrm{~g} \cdot \mathrm{L}^{-1}, \mathrm{P}(\mathrm{B})$ adalah persen kerusakan gulma akibat herbisida Bentazon 400 g. $\mathrm{L}^{-1}$, sedangkan $P(A)(B)$ adalah hasil kali persen kerusakan $P(A)$ dengan $P(B)$. Nilai LD50 harapan dapat diperoleh dari persamaan $P(A+B)=50$, dimana $P(A)$ dan $P(B)$ diperoleh dari persamaan garis probit $Y=a+b X$ (Alfredo et al., 2012). Menurut Kurniadie et al., (2020), sifat campuran dapat sinergis apabila nilai kotoksisitasnya $>1$ dan sifat akan antagonis apabila nilai kotoksisitasnya $<1$.

\section{HASIL DAN PEMBAHASAN \\ Analisis Tingkat Kerusakan}

Gejala awal gulma setelah aplikasi herbisida campuran Bentazon + MCPA 460 g. $\mathrm{L}^{-1}$ disemprotkan adalah pertumbuhan gulma Ludwigia hyssopifolia dan Sphenoclea zeylanica batang layu, dan daun gulma Sphenoclea zeylanica berwarna hijau pucat selanjutnya layu, sedangkan warna daun gulma Ludwigia hyssopifolia berwarna coklat dan mengering. Selanjutnya gulma Leptochloa chinensis dan Monochoria vaginalis mengalami klorosis pada ujung daun. Gejala ini mulai terlihat pada 4 - 10 HSA dari dosis 
terendah hingga tertinggi. Kedua jenis bahan aktif herbisida yang digunakan memiliki sifat sistemik, sehingga pengaruh herbisida belum bisa terlihat pada 1 HSA (Hari Setelah Aplikasi).

Kerusakan gulma dihitung berdasarkan analisis bobot kering bagian gulma yang rusak akibat perlakuan herbisida (Tabel 1 dan Tabel 2). Herbisida Bentazon 400 g. $\mathrm{L}^{-1}$ yang diaplikasikan secara tunggal dapat mengendalikan gulma daun lebar dimulai pada dosis tinggi yaitu 4,00 L.ha ${ }^{-1}$ dengan tingkat kerusakan sebesar $46,74 \%-92,86 \%$. Kerusakan yang terjadi pada gulma teki baru terlihat pada dosis 1,00 L.ha ${ }^{-1}$ dengan tingkat kerusakan rata-rata 55,90\% - 78,62\% (Tabel 1). Herbisida Bentazon mampu mengendalikan dengan cara menghambat fotosintesis pada fotosistem II sehingga menghambat produksi energi.

Herbisida tunggal berbahan aktif MCPA 60 g.L $\mathrm{L}^{-1}$ mampu mengendalikan gulma daun lebar maupun gulma rumput mulai dosis 2,00 L.ha ${ }^{-1}$ dengan tingkat kerusakan rata-rata sebesar 56,44\% - 100,00\%, sedangkan pengendalian terhadap gulma teki dimulai pada dosis 4 L.ha ${ }^{-1}$ dengan tingkat kerusakan 58,41\% - 96,74\%. Herbisida campuran Bentazon + MCPA 460 g. $\mathrm{L}^{-1}$ mampu mengendalikan gulma daun lebar pada dosis 0,625 L.ha ${ }^{-1}$ dengan tingkat kerusakan rata-rata $58,39 \%$ - 58,99\%, pada gulma rumput dapat mengendalikan mulai dosis $0,625 \mathrm{~g} \mathrm{~L}^{-1}$ dengan tingkat kerusakan rata-rata $76,70 \%-82,65 \%$. Sesuai dengan penelitian yang dilakukan oleh Umiyati et al., (2020) campuran Bentazon dan MCPA dapat mengendalikan gulma berdaun lebar dan teki, serta hal tersebut membuktikan bahwa pencampuran herbisida lebih efektif karena dosis aplikasi dapat ditekan lebih rendah dibanding dosis herbisida yang diaplikasi secara terpisah (Dey \& Pandit, 2020).

Tabel 1. Persentase Kerusakan Tiap Spesies Gulma

\begin{tabular}{|c|c|c|c|c|c|}
\hline \multirow[b]{2}{*}{ Perlakuan } & \multirow{2}{*}{$\begin{array}{l}\text { Dosis } \\
(\text { L.ha-1) }\end{array}$} & \multicolumn{4}{|c|}{ Gulma } \\
\hline & & $\begin{array}{c}\text { Sphenochlea } \\
\text { zeylanica }\end{array}$ & $\begin{array}{c}\text { Ludwigia } \\
\text { hyssopifolia }\end{array}$ & $\begin{array}{c}\text { Fimbristylis } \\
\text { miliacea }\end{array}$ & $\begin{array}{c}\text { Cyperus } \\
\text { iria }\end{array}$ \\
\hline \multirow{6}{*}{$\begin{array}{c}\text { Campuran } \\
\text { Bentazon + MCPA } \\
460 \mathrm{~g} \cdot \mathrm{L}^{-1}\end{array}$} & 5 & 68,55 & 100,00 & 88,49 & 100,00 \\
\hline & 2,5 & 64,73 & 95,56 & 80,69 & 90,91 \\
\hline & 1,25 & 54,74 & 94,55 & 76,70 & 82,65 \\
\hline & 0,625 & 58,39 & 58,99 & 66,07 & 74,08 \\
\hline & 0,3215 & 18,81 & 57,40 & 61,11 & 40,60 \\
\hline & Kontrol & 0,00 & 0,00 & 0,00 & 0,00 \\
\hline \multirow{6}{*}{$\begin{array}{c}\text { Bentazon } 400 \\
\text { g.L } L^{-1}\end{array}$} & 4 & 46,74 & 92,86 & 86,77 & 89,32 \\
\hline & 2 & 34,54 & 93,43 & 58,74 & 85,80 \\
\hline & 1 & 30,88 & 84,27 & 55,90 & 78,62 \\
\hline & 0,5 & 24,49 & 59,03 & 37,83 & 45,16 \\
\hline & 0,25 & 26,62 & 44,57 & 28,49 & 23,94 \\
\hline & Kontrol & 0,00 & 0,00 & 0,00 & 0,00 \\
\hline \multirow{6}{*}{ MCPA $60 \mathrm{~g} \cdot \mathrm{L}^{-1}$} & 4 & 62,37 & 100,00 & 58,41 & 96,74 \\
\hline & 2 & 56,44 & 100,00 & 32,89 & 66,50 \\
\hline & 1 & 47,90 & 67,82 & 32,85 & 44,68 \\
\hline & 0,5 & 29,65 & 45,74 & 19,98 & 15,95 \\
\hline & 0,25 & 18,52 & 29,54 & 19,78 & 12,23 \\
\hline & Kontrol & 0,00 & 0,00 & 0,00 & 0,00 \\
\hline
\end{tabular}

Tabel 2 menunjukkan bahwa herbisida campuran Bentazon + MCPA $460 \mathrm{~g} \cdot \mathrm{L}^{-1}$ mampu mengendalikan gulma sasaran dimulai pada dosis $0,625 \mathrm{~g} \cdot \mathrm{L}^{-1}$ dengan hasil persen kerusakan sebesar 58,86 \%. Penggunaan herbisida campuran Bentazon + MCPA 460 g.L-1 dapat efektif mengendalikan pada dosis yang lebih rendah dibandingkan masing-masing herbisida tunggal Bentazon 400 g.L. $\mathrm{L}^{-1}$ dan MCPA $60 \mathrm{~g} . \mathrm{L}^{-1}$. Hal tersebut membuktikan bahwa pencampuran herbisida Bentazon + MCPA 460 g. $\mathrm{L}^{-1}$ dapat memperluas spektrum pengendalian serta mengefisiensikan penggunaan dosis herbisida.

Persen kerusakan gulma merupakan rata-rata penjumlahan pada setiap ulangan dari gabungan gulma Ludwigia hyssopifolia, Sphenoclea zeylanica, Cyperus iria dan Fimbristylis miliacea (Tabel 2). Data persen kerusakan berupa persen kematian gabungan tersebut nantinya diperlukan untuk mengetahui tipe campuran herbisida Bentazon + MCPA 460 g. $\mathrm{L}^{-1}$. Nilai persen kematian kontrol tidak digunakan (nol) untuk menunjukkan bahwa tidak terdapat pengaruh herbisida.

\section{Analisis Sifat Campuran Herbisida}

Hasil analisis regresi linier sederhana dan nilai LD50 dari masing-masing perlakuan herbisida (Tabel 3). Perlakuan berbagai dosis herbisida menunjukkan hasil persentase kerusakan gulma yang berbeda. Nilai probit digunakan untuk mengetahui hubungan antara dosis perlakuan dengan persen kerusakan yang ditimbulkan oleh masing-masing herbisida. Dosis herbisida diubah ke dalam bentuk logaritmik sedangkan persen 
kerusakan diubah ke dalam nilai probit. Nilai probit yang dihasilkan kemudian digunakan untuk mencari persamaan regresi linier yaitu $y=a+b x$. Nilai $y$ merupakan transformasi nilai probit dari persentase kerusakan gulma dan $\mathrm{x}$ merupakan nilai logaritma penggunaan dosis (Hong et al., 2018). Pada transformasi nilai probit selanjutnya akan digunakan untuk menghitung nilai LD50 percobaan dan harapan. Rata-rata persen kerusakan yang telah dikonversi ke dalam nilai probit serta nilai dari LD50 perlakuan. Pencampuran herbisida dengan bahan aktif berbeda bertujuan untuk memperluas spektrum pengendalian gulma, serta diharapkan dapat memperlambat gulma yang resisten terhadap herbisida, mengurangi biaya produksi, serta mengurangi residu herbisida, sehingga lebih ekonomis dan efektif (Anwar \& Djatmiko, 2019).

Persamaan Regresi

Bentazone $400 \mathrm{~g} . \mathrm{L}^{-1}$

$y=1.4787 x+1.4601 ; R^{2}=0,995$

MCPA $60 \mathrm{~g} \cdot \mathrm{L}^{-1}$

$y=1.7361 x+0.28 ; R^{2}=0,973$

Herbisida Campuran

$y=1.7295 x+0.7723 ; R^{2}=0,9829$

Tabel 2. Persentase Kerusakan Gulma Akibat Herbisida

\begin{tabular}{|c|c|c|c|c|c|c|}
\hline Perlakuan & Dosis (L.ha-1) & Ulangan 1 & Ulangan 2 & Ulangan 3 & Ulangan 4 & Rata-rata \\
\hline \multirow{6}{*}{$\begin{array}{l}\text { Campuran Bentazone + } \\
\text { MCPA } 460 \mathrm{~g} / \mathrm{l}\end{array}$} & 0,00 & 0,00 & 0,00 & 0,00 & 0,00 & 0,00 \\
\hline & 5 & 87,34 & 86,01 & 90,56 & 72,05 & 83,99 \\
\hline & 2,5 & 71,48 & 79,52 & 88,83 & 77,93 & 79,44 \\
\hline & 1,25 & 76,32 & 78,10 & 78,45 & 68,35 & 75,31 \\
\hline & 0,625 & 65,36 & 60,85 & 56,56 & 49,45 & 58,06 \\
\hline & 0,3215 & 61,36 & 51,17 & 51,72 & 19,84 & 46,02 \\
\hline \multirow{6}{*}{ Bentazone $400 \mathrm{~g} / \mathrm{l}$} & 0,00 & 0,00 & 0,00 & 0,00 & 0,00 & 0,00 \\
\hline & 4 & 79,00 & 83,07 & 80,43 & 82,00 & 81,13 \\
\hline & 2 & 80,63 & 68,43 & 78,08 & 80,02 & 76,79 \\
\hline & 1 & 67,49 & 59,75 & 62,28 & 68,63 & 64,54 \\
\hline & 0,5 & 60,12 & 34,66 & 21,29 & 25,95 & 35,50 \\
\hline & 0,25 & 26,84 & 31,84 & 7,94 & 5,12 & 17,93 \\
\hline \multirow{6}{*}{ MCPA $60 \mathrm{~g} / \mathrm{l}$} & 0,00 & 0,00 & 0,00 & 0,00 & 0,00 & 0,00 \\
\hline & 4 & 68,17 & 72,37 & 72,01 & 48,55 & 65,28 \\
\hline & 2 & 47,11 & 57,72 & 71,20 & 61,31 & 59,34 \\
\hline & 1 & 33,28 & 42,73 & 44,66 & 54,14 & 43,70 \\
\hline & 0,5 & 36,76 & 32,58 & 41,81 & 55,43 & 41,65 \\
\hline & 0,25 & 27,81 & 44,48 & 28,02 & 48,45 & 37,19 \\
\hline
\end{tabular}

\section{Model MSM (Multiplicative Survival Model)}

Sifat campuran herbisida diperoleh dengan membandingkan nilai LD50 harapan dengan nilai LD50 percobaan. Diketahui nilai LD50 percobaan campuran herbisida Bentazon + MCPA adalah:

Tabel 3. Kerusakan Gulma oleh Herbisida Tunggal dan Campuran dan LD50

\begin{tabular}{lllllc}
\hline & \multicolumn{3}{c}{ Log Dosis } & & LD50 (g ai/ha) \\
\hline $\mathrm{y} 1=5$ & $\mathrm{x} 1=$ & 2,393927 & Antilog $x 1=$ & 247,701 \\
$\mathrm{y} 2=5$ & $\mathrm{x} 2=$ & 2,718737 & Antilog $\mathrm{x} 2=$ & 523,284 \\
$\mathrm{y} 3=5$ & $\mathrm{x} 3=$ & 2,444464 & Antilog $\mathrm{x} 3=$ & 278,268 \\
\hline
\end{tabular}

Keterangan: $\mathrm{x} 1=$ Bentazon $400 \mathrm{~g} \cdot \mathrm{L}^{-1}, \mathrm{x} 2=\mathrm{MCPA} 60 \mathrm{~g} \cdot \mathrm{L}^{-1}, \mathrm{x} 3=$ Herbisida

Perbandingan Komponen campuran Bentazon (B): MCPA (M) adalah 40:6. Berdasarkan analisis Probit, kerusakan gulma oleh Bentazon $(\mathrm{Y} 1)=45,068$. Kerusakan gulma oleh MCPAI $(Y 2)=8,798$. Persamaan probit tingkat kerusakan gulma oleh setiap komponen campuran dihitung sebagai berikut:
$\mathrm{P}(\mathrm{A}+\mathrm{B})$$$
=P(A)+P(B)-P(A)(B)
$$$$
=45,068+8,798-4,05
$$$$
=50 \%
$$
LD50 Harapan
LD50 percobaan

$$
=292,470 \mathrm{~g} \text { ai.ha }^{-1}
$$$$
=278,268 \mathrm{~g} \text { ai.ha }^{-1}
$$
Berdasarkan hasil perhitungan LD50 percobaan

lebih kecil dibandingkan LD50 harapan, nilai kotoksisitas $=1,8$, atau lebih dari satu $(>1)$, hal ini menunjukkan bahwa campuran kedua herbisida (Bentazon $400 \mathrm{~g} . \mathrm{L}^{-1}$ dan MCPA $60 \mathrm{~g}$. $\mathrm{L}^{-1}$ ) menghasilkan sifat yang sinergis, dikatakan sinergis dikarenakan nilai kerusakan herbisida lebih tinggi dibandingkan dengan kerusakan yang disebabkan oleh herbisida tunggal (Fitria et al., 2017).

Bentazon dan MCPA adalah herbisida yang memiliki perbedaan golongan kimia yaitu Benzothiadiazoles dan phenoxy acetic acid yang menghambat terjadinya fotosintesis pada fotosistem II dan mengganggu 
pertumbuhan gulma dengan auksin sintesis. Sun et al., (2021) menyatakan apabila terdapat perbedaan golongan bahan kimia, mode of action (cara kerja), campuran herbisida dapat saling berinteraksi untuk menghambat kerja enzim atau proses fisiologis gulma.

\section{KESIMPULAN}

Pencampuran herbisida Bentazon $400 \mathrm{~g} \cdot \mathrm{L}^{-1}+\mathrm{MCPA}$ 60 g.L-1 memiliki LD50 percobaan sebesar 0,3857 L.ha-1 dan LD50 harapan sebesar 0,6943 L.ha-1, dengan nilai kotoksisitasnya yaitu 1,8 (>1) sehingga sifat campuran herbisida bersifat sinergis.

\section{DAFTAR PUSTAKA}

Alfredo, N., Sriyani, N., \& Sembodo, D. R. J. (2012). Efikasi herbisida pratumbuh metil metsulfuron tunggal dan kombinasinya dengan 2,4-d, ametrin, atau diuron terhadap gulma pada pertanaman tebu (Saccharum officinarum L.) Lahan Kering. Jurnal Agrotropika, 17(1), 29-34.

Anwar, R., \& Djatmiko, D. (2019). Aplikasi herbisida ramah lingkungan pada kelompok tani desa kungkai baru kecamatan air periukan kabupaten seluma. Abdihaz: Jurnal Ilmiah Pengabdian Pada Masyarakat, 1(1), https://doi.org/10.32663/abdihaz.v1i1.749

Dey, P., \& Pandit, P. (2020). Review article relevance of data transformation techniques in weed science. Journal of Research in Weed Science, 3(1), 81-89. https://doi.org/10.26655/JRWEEDSCI.2020.1.8

Ferreira, P. H. U., Thiesen, L. V., Pelegrini, G., Ramos, M. F. T., Pinto, M. M. D., \& da Costa Ferreira, M. (2020). Physicochemical properties, droplet size and volatility of dicamba with herbicides and adjuvants on tank-mixture. Scientific Reports, 10(1), 1-11. https://doi.org/10.1038/s41598-020-75996-5

Fitria, Purba, E., \& Sabrina, T. (2017). Pertumbuhan dan produksi jagung (Zea mays. I) pada berbagai pengelolaan gulma di kabupaten deli serdang. Jurnal Pertanian Tropik, 4(3), 9-15.

Garrigou, A., Laurent, C., Baldi, I., Berthet, A., Colosio, C., Daubas-Letourneux, V., Galey, L., Goutille, F., Jackson Filho, J. M., Jas, N., Jouzel, J. N., Judon, N., Lebailly, P., \& Samuel, O. (2021). Response from the authors of the article "Critical review of the role of personal protective Equipment (PPE) in the prevention of risks related to agricultural pesticide use" to the letter to the editor from the European crop protection association (ECPA) Occupational and bystander exposure expert group (OBEEG). Safety Science, 138, 105191. https://doi.org/10.1016/j.ssci.2021.105191

Hong, Y., Yang, X., Huang, Y., Yan, G., \& Cheng, Y. (2018). Assessment of the oxidative and genotoxic effects of the glyphosate-based herbicide roundup on the freshwater shrimp, Macrobrachium nipponensis. Chemosphere, 210, 896-906. https://doi.org/10.1016/j.chemosphere.2018.07.069
Jones, E. A. L., \& Owen, M. D. K. (2021). Investigating the efficacy of selected very-long-chain fatty acidinhibiting herbicides on iowa waterhemp ( Amaranthus tuberculatus ) populations with evolved multiple herbicide resistances. Agronomy, 595(11), $1-9$.

Kurniadie, D., Purbayanti, D. A., \& Sumekar, Y. (2020). Sinergisme Campuran herbisida berbahan aktif ipa glifosat $240 \mathrm{~g} / \mathrm{l}$ dan 2,4 D amina $120 \mathrm{~g} / \mathrm{l}$ dalam mengendalikan beberapa jenis gulma. Agrikultura, 30(3),134.https://doi.org/10.24198/agrikultura.v30i3. 24831

MacLaren, C., Storkey, J., Menegat, A., Metcalfe, H., \& Dehnen-Schmutz, K. (2020). An ecological future for weed science to sustain crop production and the environment. A review. Agronomy for Sustainable Development, 40(4). https://doi.org/10.1007/s13593020-00631-6

Moshiur Rahman. (2012). Response of weed flora to different herbicides in aerobic rice system. Scientific Research and Essays, 7(1), 12-23. https://doi.org/10.5897/sre11.362

Polansky, S., \& Guntoro, D. (2016). Pengendalian gulma pada tanaman padi sawah dengan menggunakan herbisida berbahan aktif campuran bentazon dan MCPA. Buletin Agrohorti, 4(1), 122-131. https://doi.org/10.29244/agrob.v4i1.15011

Shekhawat, K., Rathore, S. S., \& Chauhan, B. S. (2020). Weed management in dry direct-seeded rice: $A$ review on challenges and opportunities for sustainable rice production. Agronomy, 10(9). https://doi.org/10.3390/agronomy10091264

Sun, Y., Kaleibar, B. P., Oveisi, M., \& Müller-Schärer, H. (2021). Addressing climate change: what can plant invasion science and weed science learn from each other? Frontiers in Agronomy, 2(December). https://doi.org/10.3389/fagro.2020.626005

Umiyati, U, Widayat, D., Kurniadie, D., \& Gumiwang. (2020). Herbisida penoksulam $25 \mathrm{~g} / \mathrm{L}$ sebagai pengendali gulma teki dan daun lebar pada budidaya padi sawah sistem tanam pindah Penoxsulam $25 \mathrm{~g} /$ $\mathrm{L}$ herbicide as sedges and broadleaves weed control on paddy cultivation through transplanting Pendahuluan. Jurnal Kultivasi, 19(2), 1105-1113.

Umiyati, Uum, Kurniadie, D., Widayat, D., Sumekar, Y., \& lim, A. (2018). Efektivitas herbisida bentazone sodium (370 g/L) dan MCPA DMA (62 g/L) dalam mengendalikan gulma pada budidaya padi sawah. Kultivasi, $17(3)$, https://doi.org/10.24198/kultivasi.v17i3.18731

Zarwazi, L. M., Chozin, M. A., \& Guntoro, D. (2016). Potensi gangguan gulma pada tiga sistem budidaya padi sawah. Jurnal Agron Indonesia, 44(2), 147-153. 